\section{$\underset{\substack{\text { hommes } \\ \text { \& migrations }}}{ }$}

\section{Hommes \& migrations}

Revue française de référence sur les dynamiques

migratoires

$1332 \mid 2021$

Ce qui s'oublie et ce qui reste

\title{
Camille Schmoll, Les damnées de la mer. Femmes et
}

frontières en Méditerranée

Paris, La Découverte, 2020, 248 p., $20 €$.

\section{Marie Poinsot}

\section{(e) OpenEdition}

Journals

Édition électronique

URL : https://journals.openedition.org/hommesmigrations/12488

DOI : 10.4000/hommesmigrations. 12488

ISSN : 2262-3353

Éditeur

Musée national de l'histoire de l'immigration

Édition imprimée

Date de publication : 1 janvier 2021

Pagination : 268-269

ISBN : 978-2-919040-54-4

ISSN : 1142-852X

Référence électronique

Marie Poinsot, "Camille Schmoll, Les damnées de la mer. Femmes et frontières en Méditerranée ",

Hommes \& migrations [En ligne], 1332 | 2021, mis en ligne le 01 janvier 2021, consulté le 26 juillet 2021.

URL : http://journals.openedition.org/hommesmigrations/12488; DOI : https://doi.org/10.4000/

hommesmigrations. 12488 


\section{Les damnées de la mer. Femmes et frontières en Méditerranée}

Camille Schmoll, Paris, La

Découverte, 2020, 248 p., $20 €$.

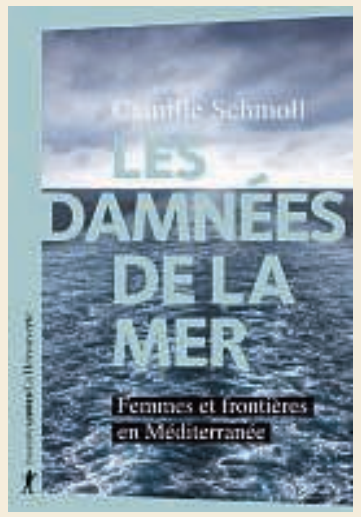

À partir de travaux menés à Malte et en l'Italie - notamment en Sicile -, pays méditerranéens placés « en ligne de front sur les voies de passage » maritime, cet ouvrage porte sur les femmes africaines qui prennent la route vers l'Europe. Camille Schmoll mène une ethnographie de ces femmes en circulation, ni victimes, ni héroïnes, dans leurs expériences de la frontière et des politiques de contrôle des flux en postulant: " Si elles sont des survivantes, elles sont également des aventurières, des stratèges, des meneuses parfois » (p. 13). À cette occasion, l'auteure propose une synthèse critique des travaux récents sur « la vie au temps des frontières » qui ont totalement renouvelé l'approche géopolitique. Car le contexte a changé drastiquement depuis deux décennies avec le prolongement de la frontière dans l'espace européen, la complexité accrue du jeu des acteurs institutionnels et humanitaires et le rôle croissant des passeurs. Cette expérience de la frontière s'est élargie spatialement et devient parfois interminable ; ce que Michel Agier qualifie de «couloir des exilés». Depuis la mise en place de l'agence Frontex en 2004 , le passage irrégulier est devenu un point focal des travaux sur les migrations féminines vers l'Europe, au détriment des études sur les mobilités intra-européennes ou sur les migrations familiales qui, à partir des années 1973-1974, avaient pourtant contribué à la visibilité de la migration féminine. La gestion humanitaire de l'urgence constitue le chantier le plus actif des recherches. L'auteure analyse comment ces femmes s'installent dans la circulation, reconfigurent leurs projets de mobilité et d'immobilité, souvent malmenées par des stratégies à court terme.

L'ouvrage valorise la place des femmes dans les migrations en Méditerranée comme "sujets sociaux 》 et comme " actrices de leur histoire », tout en insistant sur leur vulnérabilité et leur surmortalité, statistiquement 
prouvée, notamment en raison des violences genrées qu'elles subissent dans leur survie et qui laissent des traumatismes corporels et mentaux lourds. La grande originalité de cet essai est de montrer que la migration est une épreuve du corps avant tout, dont Camille Schmoll décrit avec détails les effets (l'épuisement, le stress, la souffrance, la privation de liberté, la dégradation, la précarité, etc.). Le corps est appréhendé comme une ressource des stratégies migratoires, mais aussi comme le siège et l'enjeu des dynamiques identitaires. Dans l'installation des femmes à la marge, le soin du corps mis à l'épreuve est perçu comme un retour sur soi et une manière de se reterritorialiser pour éventuellement poser des ancrages en mobilité.

L'auteure souligne également le paradoxe du projet migratoire pour ces femmes. Si la migration des femmes répond à un désir d'autonomisation individuelle et familiale, de promotion sociale et de liberté corporelle, les démarches de régularisation des statuts et d'accès aux programmes publics d'accueil et d'intégration les exposent à des risques de déclassement social et à des années d'impasse juridique. Pour Camille Schmoll, les femmes vivent l'expérience de la marge dans tous les actes de la vie quotidienne dans un contexte d'« autonomie en tension », c'est-à-dire sous contrainte des formes de pouvoir et de rapports sociaux qui limitent "l'insoumission de la liberté » (Michel Foucault) propre au projet migratoire. Même quand ces femmes adoptent un destin entrepreneurial face à la déqualification ou aux discriminations sur le marché du travail, elles deviennent les " servantes de la mondialisation» (Rhacel Parreñas). Par ailleurs, l'auteure montre que la migration redéfinit les zones de l'intimité et des féminités. La migration est aussi une quête du droit à l'intimité. Voulant négocier au quotidien leur espace domestique et un espace à soi - parfois religieux et culturel -, elles sont de nouveau contraintes de se forger une niche d'intimité sous contraintes multiples, sorte d'hybridation du privé et du public. L'usage d'Internet répond à la quête d'un espace de repli, de refuge, mais aussi espace de mise en scènes de la migration et d'expression des émotions, et déploiement en images du corps entravé et violenté dans son intimité et sa dignité ; il participe à la construction "renarcissante », revalorisante de soi, mais aussi aux communications transnationales qui permettent aux relations familiales et sociales de se maintenir entre l'ici et là-bas. Issue d'une thèse d'habilitation à diriger des recherches soutenue en 2017 à l'université de Poitiers, cet essai est d'une lecture passionnante et fluide pour une audience de nonspécialistes. Ainsi, les nombreux témoignages qui rythment l'analyse donnent la parole aux femmes et interrogent « l'illusion biographique » des récits de migrantes comme ressources à des investigations scientifiques, car « il y a des centaines, des milliers de Julienne » dont «la réalité dépasse la fiction $»$.

Marie Poinsot 